\title{
Is Price Dynamics Homogeneous Across Eurozone Countries?
}

\author{
David Guerreiro \\ University of Paris Ouest, EconomiX-CNRS \\ Marc Joëts \\ University of Paris Ouest, EconomiX-CNRS \\ Valérie Mignon \\ University of Paris Ouest, EconomiX-CNRS and CEPII
}

\begin{abstract}
The aim of this paper is to investigate whether price dynamics is homogeneous across the Eurozone countries. Relying on monthly data over the January 1970 July 2011 period, we test for the absolute purchasing power parity (PPP) hypothesis through the implementation of second and third-generation panel unit root and cointegration tests. Our results show that price dynamics are heterogeneous depending on both the time period and the considered group of countries. More specifically, while PPP is validated for the core Economic Monetary Union (EMU) countries, this hypothesis does not hold for Northern peripheral economies. Turning to the Southern countries, PPP is observed only before the launch of the euro.
\end{abstract}

JEL Classifications: C23, E31, F15, F41.

Key Words: Price Convergence, Eurozone, Panel Unit Root Tests, Half-Life.

\footnotetext{
* Corresponding Author: Valérie Mignon; EconomiX-CNRS, University of Paris Ouest, 200 avenue de la République, 92001 Nanterre Cedex, France, Tel: +33 (0)1 409758 60, Fax: +33 (0)1 4097 77 84, Email: valerie.mignon@u-paris10.fr;

Co-Author: David Guerreiro; EconomiX-CNRS, University of Paris Ouest, Email: david.guerreiro@u-paris10.fr, Marc Joets; EconomiX-CNRS, University of Paris Ouest, Email: marc.joets@u-paris10.fr.
} 


\section{Introduction}

Since 2009, the EMU (Economic Monetary Union) has been experiencing serious economic troubles that now challenge its stability, and, to a certain extent, its existence. Triggered by high debt ratios relative to GDP, high deficits, and low growth expectations, a sovereign debt crisis has arisen in peripheral countries. Greece, Ireland and Portugal have been forced to ask the Troïka for financial assistance while Spain, even if it has succeeded to avoid such assistance, has experienced a large increase in its debt financing costs. The crisis has also reached the core of EMU as evidenced by the large increase of spreads between Italian and German bonds, and, to a lesser extent, between French and German bonds.

If the roots of such a crisis are obviously multiple, one of the main reasons would be the possible heterogeneity of price dynamics among members. In order to constitute a viable currency area, the founding members of the Eurozone have developed, since the beginning of the EMU, a number of rules to ensure economic convergence as stated in the Maastricht Treaty (1992) completed by the Pact of Stability and Growth (1997). One of the crucial rules is surely price stability: members' inflation rates should not exceed 1.5 points the mean of the three lowest inflation rates. Although this is intended to render the "one-size-fits-all" monetary policy efficient, it also has consequences on the price dynamics that may differ with the reality of the EMU. Inside a monetary union, implementing the convergence of inflation rates is intended to avoid asymmetric disequilibria coming from a loss of price competitiveness. However, it also supposes strong economic homogeneity regarding per capita income and productivity levels. More importantly, inflation rate convergence in a monetary union also implies price levels to be close to those determined by the absolute purchasing power parity (PPP) hypothesis.

Such a constraint may be viewed as very strong given the economic differences between the core of the EMU and its periphery. The Balassa-Samuelson phenomenon inducing price catch-up is expected in peripheral countries, leading to heterogeneous convergence speeds depending on the group of countries (the extreme case being non convergence of price levels) and challenging absolute and, hence, relative PPP. In that case, common monetary policy may be inadequate because of its pro-cyclicality. On one hand, it could be too restrictive for advanced economies and may lead to deflationary pressures. On the other hand, it could be pandering for countries experiencing a catch-up. Because of negative or low real interest rates, debt bubbles may appear, exacerbating internal imbalances (excess leverage, asset price bubbles) and external deficits. Testing for absolute price convergence would allow us to investigate whether these processes may have materialized after the launch of the euro, which partly contributes to the sovereign debt crisis.

Only a few papers deal with price convergence inside the EMU. Articles generally focus

Namely, EU, ECB, and IMF. 
on the reasons explaining heterogeneity in inflation rates (see, for example, Engel and Rogers, 2001; Honohan and Lane, 2003; Arnold and Verhoef, 2004), but very few investigate price dynamics empirically (i.e., validation of absolute PPP) mainly because of the lack of available data. The differences among the existing studies come from the datasets used. Some rely on microdata (Engel and Rogers, 2004; Crucini et al., 2005; and Rogers, 2007) while others use aggregate data (Camarero et al., 2000; Allington et al., 2005; Faber and Stockman, 2009).

Among the studies using microdata panels, Engel and Rogers (2004) and Rogers (2007) consider data from the Economic Intelligence Unit and pay attention to the price of "standard" goods measured in 18 cities belonging to the Eurozone. They find a reduction of price dispersion during the implementation of the Single Act (1986), but the introduction of the euro seems to have had little effect. Crucini et al. (2005) test the validity of LOOP (Law of One Price) using Eurostat data for four different years $(1975,1980,1985$, and 1990). They show that LOOP is violated only for a small number of products, tending to validate absolute PPP.

Studies using aggregate data provide results that go in the same direction. Camarero et al. (2000) evidence a catch-up effect for peripheral countries (Spain, Italy, and UK) relative to Germany by implementing time series unit root tests with structural breaks on consumer price index (CPI) differentials. ${ }^{2}$ Allington et al. (2005), employing Comparative Price Levels (CPLs) provided by Eurostat, put forward a significant effect of the euro on price dispersion. By recalculating CPIs that account for price level differentials among countries, Faber and Stockman (2009) uphold the diminution in price dispersion across Eurozone countries. Finally, Guerreiro and Mignon (2011) highlight some heterogeneity across the Eurozone members in terms of price convergence speed that can be explained by the evolution of price competitiveness, rigidities on the labor market, and technological specialization patterns.

Our aim in this paper is to investigating the homogeneity of price dynamics inside EMU over the January 1970 to July 2011 period to contribute to this literature that is still in its infancy. We show that achieving absolute PPP is one of the conditions for maintaining the price stability necessary in keeping the monetary union viable. To investigate price convergence, therefore, we rely on unit root and cointegration tests. We go further than the usual time series and panel tests by accounting for both heterogeneity and cross-section dependence through the implementation of second-generation panel unit root tests, as well as structural breaks using third-generation panel tests. We also assess speeds of price convergence using the Pooled Mean Group (PMG) estimator of Pesaran, Smith, and Shin (1999).

The rest of the paper is organized as follows. Section 2 presents the theoretical framework and the data; Section 3 displays the results of unit root tests and PMG estimates; Section 4 discusses our findings; and Section 5 concludes the article.

\footnotetext{
${ }^{2}$ We will evidence in Section 2 that this methodology is very questionable since CPI does not account for differences in price levels.
} 


\section{Theoretical Backgrounds and Data}

\section{A. Theoretical Backgrounds}

In a two-country model, absolute PPP is defined by:

$$
e_{t}=p_{t}-p_{t}^{*}
$$

where $e_{t}$ is the $\log$ of the spot exchange rate and $p_{t}$ and $p_{t}^{*}$ respectively denote the $\log$ of the domestic and foreign price levels. Relative PPP holds when:

$$
\Delta e_{t}=\Delta p_{t}-\Delta p_{t}^{*}
$$

with $\Delta e_{t}$ denoting the variation of the log of the exchange rate and $\Delta p_{t}$ and $\Delta p_{t}^{*}$ the inflation rates of domestic and foreign country. If we assume now that these countries form a monetary union with a single currency, $e_{t}=0$, and it comes for absolute PPP:

$$
p_{t}-p_{t}^{*}=0
$$

while relative PPP becomes:

$$
\Delta p_{t}-\Delta p_{t}^{*}=0
$$

Plugging (3) and (4), we get:

$$
p_{t}-p_{t}^{*}=\Delta p_{t}-\Delta p_{t}^{*}
$$

Consequently, absolute and relative PPPs are equivalent in a monetary union. In other words, convergence in inflation rates is conditioned by the fact that price levels are the same among countries. If price levels differ, the viability of the monetary area is challenged in the long run. Countries that have lower price levels are expected to catch up their delay (BalassaSamuelson effect), leading to higher inflation rates which goes against relative PPP inside a currency union. In a highly integrated currency union where trade barriers have disappeared, and assuming that the adjustment towards absolute PPP is made only through the goods market, a violation of absolute PPP "signals an imbalance in the goods markets which [...] is likely to result in trade deficits" (Juselius, 2003). Capital inflows (thanks to borrowing) are necessary to recover the equilibrium of the balance of payments. However, these massive inflows pressure upward nominal interest rates of low-price countries leading to an increase of the spreads rela- 
tive to high price-level countries. Accumulation of deficits also leads to an increase of a debt level which in turns raises the risk premium that traduces the default risk. The combined effects of these two mechanisms that reveals the mistrust to currency union viability entails prohibitive financing rates, leading to a sovereign debt crisis that spills over the union. This can be seen as a pure asymmetric shock as that presented by Mundell (1961) in a seminal paper on Optimum Currency Areas (OCA) that challenges the existence of the currency union.

\section{B. Data}

To test for absolute PPP, the price levels of Eurozone countries are needed. CPIs are unusable since they do not account for price level differentials among countries; they only depict the evolution of prices. To overcome this issue, we rely on the International Comparison Program (ICP) carried by the World Bank that aims at providing comparable international prices. Based on this framework, Eurostat and Organization for Economic Cooperation and Development (OECD) have computed the Comparative Price Level (CPL) series for each European country. These CPLs are defined by the OECD as the ratio between purchasing power parity conversion factor for private consumption ${ }^{3}$ and the nominal exchange rate. This ratio measures price level differences between two countries (in our case between a European country and the United States) and can be expressed as follows:

$$
C P L_{i, t}=\frac{P P P_{i, t}}{N E R_{i, t}} \times 100
$$

where $P P P_{i, t}$ stands for the PPP conversion factor for private final consumption of country $i$ relative to the United States at time $t$, expressed in euros per US dollar, and $N E R_{i, t}$ is the euro/dollar exchange rate at time $t$. Turning to data availability, CPLs are computed by Eurostat and OECD for each European country annually only since 1995. It is, however, possible to recover observations prior to 1995 using the price evolution relative to the US in each European country; i.e., using the relative CPIs corrected by the exchange rate variations. More specifically, we construct the monthly domestic price level series of country $i$ on the period from January 1970 to July 2011 as follows ${ }^{4}$ :

\footnotetext{
${ }^{3}$ Following the World Bank definition, the PPP conversion factor for private consumption is the number of units of a country's currency required to buy the same amount of goods and services in the domestic market as a US dollar would buy in the United States, the conversion factor being applicable to private consumption.

${ }^{4}$ See Guerreiro and Mignon (2011). Note that to construct the price level series, it is assumed that the reference goods basket has remained the same over the 1970 1995 period.
} 


$$
P_{i, t}=\frac{P P P_{i, 2005}}{N E R_{i, 2005}} \times \frac{\frac{C P I_{i, t}}{C P I_{i, 2005}}}{\frac{N E R_{i, t}}{N E R_{i, 2005}} \times \frac{C P I_{U S, t}}{C P I_{U S, 205}}} \times 100
$$

where $i=1, \ldots, 12$ denotes the European country. $P P P_{i, 2005}$ is the PPP for private consumption for country $i$ relative to the US in 2005 (euros per US dollar). $C P I_{i, \mathrm{t}}, C P I_{i, 2005}, C P I_{u s, \mathrm{t}}$, and $C P I_{u s, 2005}$ are respectively the country $i$ 's CPI at time $t$ and at year 2005, and the US CPI at time $t$ and at year 2005. $N E R_{i, 2005}$ is the euro/dollar exchange rate in year 2005. 2005 has been chosen as the basis year because it corresponds to the year of the last ICP survey realized by the World Bank. From Equation (7), we thus obtain 12 series of price levels ${ }^{6}$ that can be used to test for price convergence (see Figure 1 in the Appendix). Given the importance of Germany in the Eurozone, we retain this country as the benchmark and investigate the PPP between each domestic price level series and the German one.

\section{Tests and Estimation Results}

\section{A. Time Series Analysis}

To assess the PPP between each Eurozone member and Germany, we rely on unit root and cointegration techniques by estimating an ADF-type equation ${ }^{8}$ :

$$
\Delta x_{t}=k+\phi x_{t-1}+\sum_{i=1}^{p} \phi_{i} \Delta x_{t-i}+\varepsilon_{t}
$$

where $x_{t}$ denotes the differential between domestic $\left(P_{t}\right)$ and German $\left(P_{t}^{*}\right)$ prices (in $\operatorname{logs})$ :

$$
x_{t}=\ln P_{t}-\ln P_{t}^{*}
$$

When the null hypothesis $\phi=0$ in Equation (8) is rejected, the price differential is non-

\footnotetext{
${ }^{5}$ The $P P P$ series are extracted from the OECD database. NER and CPI series are from IFS, except the German and the Irish CPIs that come from Datastream.

${ }^{6}$ Note that since our price levels have a common benchmark, the US, our series already account for nominal exchange-rate variations.

${ }^{7}$ In a previous version of the paper, a Eurozone price series was constructed, and PPP was investigated between each domestic price level series and the aggregate price level series of the 11 respective partners. The results were similar to those reported here, illustrating the robustness of our results to the choice of the benchmark price level series.

${ }^{8}$ Previous to the application of cointegration tests, a battery of unit root tests has been applied showing that all price series are integrated of order one. The detailed results are available upon request from the authors. Note that Equation (8) does not include a deterministic trend, the latter being non significant.
} 
stationary, meaning that PPP does not hold. In the case where the null is rejected, it is possible to calculate the half-life of deviations $(-\ln (2) / \ln (1+\phi)$ which provides an indication regarding the speed of price mean reversion.

As evidenced by the typology of Balassa (1961), monetary union is supposed to be the final stage of an economic integration process. Integration tends to make disappear the "border effects," that are the measures intended to discriminate foreign goods and services relative to domestic ones. There are several kinds of discriminations: tariff barriers (as custom duties), non-tariffs (quotas), or institutional tools (money). All these obstacles are found to hamper PPP. Consequently, we consider three subperiods that are in line with the different steps of EMU construction. The first period, starting in January 1970, sticks with the Common Market (established by the Rome Treaty in 1953) and ends in June 1987 with the implementation of the Single Act. The latter defines the beginning of the second period, spanning from July 1987 to December 1998. The last period starts with the introduction of the euro in January 1999 and ends in July 2011. Those periods, which are distinguished here according to the integration process, are also characterized by different exchange rate regimes: a "smooth" European Monetary System (EMS) allowing some parity adjustments for the first period; a strengthening of fixed exchange rates within the EMS, with decreasing possibilities of parity adjustments and the start of a nominal convergence process to meet Maastricht criteria and to enter in the monetary union for the second period; and an introduction of the monetary union in the third period.

Table 1. Cointegration Tests Results (ADF-type tests)

\begin{tabular}{|c|c|c|c|c|c|c|}
\hline \multirow{2}{*}{} & \multicolumn{2}{|c|}{$\mathbf{1 9 7 0 . 0 1} \mathbf{1 9 8 7 . 0 6}$} & \multicolumn{2}{c|}{$\mathbf{1 9 8 7 . 0 7} \mathbf{1 9 9 8 . 1 2}$} & \multicolumn{2}{c|}{$\mathbf{1 9 9 9 . 0 1 ~ 2 0 1 1 . 0 7}$} \\
\cline { 2 - 7 } & p-value & Half-life & p-value & Half-life & p-value & Half-life \\
\hline Austria & $0.0700^{*}$ & 48 & $0.0001 * * *$ & 0.2 & 0.6677 & \\
\hline Belgium & 0.3824 & & 0.2513 & & 0.8373 & \\
\hline Finland & 0.7334 & & 0.7609 & & 0.1358 & \\
\hline France & $0.0661^{*}$ & 2 & 0.5410 & & 0.3531 & \\
\hline Greece & 0.1180 & & 0.5343 & & 0.9717 & \\
\hline Ireland & 0.6870 & & 0.5132 & & 0.1236 & \\
\hline Italy & 0.3395 & & 0.6533 & & 0.1715 & \\
\hline Luxembourg & 0.3450 & & 0.1222 & & 0.7061 & \\
\hline Netherlands & 0.3198 & & 0.3442 & & $0.0969^{*}$ & 1.6 \\
\hline Portugal & 0.1846 & & $0.0402^{* *}$ & 9.8 & $0.0050^{* * *}$ & 12.5 \\
\hline Spain & 0.3441 & & 0.6428 & & $0.0008^{* * *}$ & 5.5 \\
\hline
\end{tabular}

(Note) $* * *($ resp. $* *, *)$ is the rejection of the null hypothesis of no cointegration at the $1 \%$ (resp. $5 \%, 10 \%$ ) significance level. Half-lives are expressed in years.

(Source) Guerreiro and Mignon (2011). 
Results of cointegration tests are presented in Table 1 which displays the $p$-values relating to the ADF-type test and the half-life of deviations (in years). With the exception of some few special cases, ${ }^{9}$ PPP does not hold since the tests fail to reject the null hypothesis of no cointegration between domestic and German prices. These poor results and the absence of obvious convergence may come from the well-known low power of time series unit root tests against the stationary alternative in small samples. Indeed, it is a well-established fact that problems of size and power are frequently associated with traditional unit root tests; in particular, they have low power (i) against $\mathrm{I}(0)$ alternatives that are close to being I(1), and (ii) when deterministic terms are added in the test regression.

To overcome these limitations, we implement the four efficient tests proposed by $\mathrm{Ng}$ and Perron (2001) which have three main advantages over the usual unit root tests: (i) no severe size distortion in the presence of large negative moving average or autoregressive roots in the error process, (ii) power gain due to the use of a GLS detrending procedure of the data, and (iii) size and power gains resulting in the use of the modified AIC criterion (MAIC) to select the lag order $p$ in the test regression (8). ${ }^{10}$ Table 2 reports the results of the $\mathrm{Ng}$ and Perron (2001) efficient modified Phillips-Perron tests, as well as the efficient modified Sargan and Bhargava (1983) and Elliott et al. (1996) tests. The results globally confirm those obtained in Table 1 regarding all subperiods, failing to support the PPP hypothesis and putting forward the absence of strong convergence processes among price series.

\footnotetext{
${ }^{9}$ At the $1 \%$ significance level, the null hypothesis of no cointegration is rejected for Portugal and Spain at the end of the period, and for Austria during the second subperiod. Note, however, that half-lives for Portugal and Spain are quite long, meaning that reversion to PPP, when it exists, takes a long time.

${ }^{10}$ As noticed by $\mathrm{Ng}$ and Perron (2001), the proper choice of the lag length is crucial to obtain good size and power properties. To this end, they suggest the use of MAIC instead of the usual AIC which is not well suited for integrated data. The code for implementing the Ng and Perron (2001) test is available on Pierre Perron's homepage: http://people.bu.edu/perron/code.html.
} 
Table 2. Ng and Perron (2001) Tests Results

\begin{tabular}{|c|c|c|c|c|c|}
\hline & \multicolumn{5}{|c|}{$1970.01 \sim 1987.06$} \\
\hline & Lag & $M Z_{\alpha}$ & $M Z_{\tau}$ & MSB & MERS \\
\hline Austria & 9 & -10.89 & -2.30 & 0.21 & 8.52 \\
\hline Belgium & 1 & -5.55 & -1.64 & 0.30 & 4.49 \\
\hline Finland & 1 & -5.40 & -1.64 & 0.30 & 16.87 \\
\hline France & 1 & $-8.25^{* *}$ & $-2.01 * *$ & 0.22 & $3.02 * *$ \\
\hline Greece & 4 & -1.70 & -0.74 & 0.44 & 11.79 \\
\hline Ireland & 12 & -7.26 & -1.90 & 0.26 & 12.56 \\
\hline Italy & 2 & -1.86 & -0.96 & 0.52 & 13.10 \\
\hline Luxembourg & 2 & -7.10 & -1.88 & 0.27 & 12.84 \\
\hline Netherlands & 3 & -4.19 & -1.32 & 0.32 & 20.54 \\
\hline Portugal & 1 & $-8.55^{* *}$ & $-1.99 * *$ & 0.23 & 3.14 \\
\hline \multirow[t]{3}{*}{ Spain } & 1 & -12.44 & -2.46 & 0.20 & 7.50 \\
\hline & \multicolumn{5}{|c|}{ 1987.07 1998.12 } \\
\hline & Lag & $M Z_{\alpha}$ & $M Z_{\tau}$ & MSB & MERS \\
\hline Austria & 11 & -4.54 & -1.50 & 0.33 & 5.40 \\
\hline Belgium & 0 & -5.96 & -1.64 & 0.28 & 4.37 \\
\hline Finland & 1 & -4.23 & -1.44 & 0.34 & 21.43 \\
\hline France & 0 & -7.19 & -1.88 & 0.26 & 12.70 \\
\hline Greece & 6 & -10.49 & -2.29 & 0.22 & 8.70 \\
\hline Ireland & 2 & -3.60 & -1.31 & 0.36 & 24.76 \\
\hline Italy & 4 & -4.74 & -1.52 & 0.32 & 19.11 \\
\hline Luxembourg & 5 & -5.89 & -1.71 & 0.29 & 4.17 \\
\hline Netherlands & 6 & -3.77 & -1.16 & 0.31 & 21.31 \\
\hline Portugal & 1 & -2.76 & -1.14 & 0.41 & 31.86 \\
\hline \multirow[t]{3}{*}{ Spain } & 4 & -1.73 & -0.93 & 0.54 & 14.09 \\
\hline & \multicolumn{5}{|c|}{ 1999.01 2011.07 } \\
\hline & Lag & $M Z_{\alpha}$ & $M Z_{\tau}$ & MSB & MERS \\
\hline Austria & 10 & -5.73 & -1.65 & 0.29 & 15.82 \\
\hline Belgium & 0 & -16.29 & -2.76 & 0.17 & 6.15 \\
\hline Finland & 12 & -6.39 & -1.65 & 0.26 & 4.28 \\
\hline France & 12 & -2.21 & -0.99 & 0.45 & 10.65 \\
\hline Greece & 12 & -17.25 & -2.93 & 0.17 & 5.88 \\
\hline Ireland & 12 & -2.05 & -0.91 & 0.44 & 10.97 \\
\hline Italy & 3 & -3.07 & -1.14 & 0.37 & 27.35 \\
\hline Luxembourg & 12 & -1.15 & -0.54 & 0.49 & 49.76 \\
\hline Netherlands & 12 & -8.45 & -2.00 & 0.24 & 10.97 \\
\hline Portugal & 12 & -10.18 & -2.17 & 0.21 & 9.34 \\
\hline Spain & 12 & -6.46 & -1.60 & 0.25 & 14.17 \\
\hline
\end{tabular}


(Note) $* *$ is the rejection of the null hypothesis of no cointegration at the $5 \%$ significance level. $M Z_{\alpha}$ is the modified version of the $Z_{\alpha}$ Phillips-Perron test; $M Z_{\tau}$ is the modified version of the $Z_{\tau}$ Phillips-Perron test; MSB is the modified Sargan-Bhargava (1983) test; MERS is the modified Elliott et al. (1996) test. The number of lags has been selected using the modified AIC criterion.

Given that we have divided our sample in three subperiods by imposing the break locations, it would be interesting to complement our analysis using unit root and cointegration tests that endogenously detect those structural breaks. For the sake of completeness, we consequently apply two tests that account for discontinuities in the series: the Lee and Strazicich (2003) unit root test ${ }^{11}$ and the Gregory and Hansen (1996) cointegration test. Recall that the Lee and Strazicich (2003) test allows for a break under both the null and the alternative hypotheses, and that the Gregory and Hansen (1996) test considers the null of non-cointegration against the alternative of cointegration, with a structural break endogenously detected in the long-term relationship. With the exception of France for the Lee and Strazicich (2003) test, results given in Table 3 show that the null hypothesis is never rejected, going against PPP and underlining the absence of obvious convergence.

Table 3. Results of Unit Root and Cointegration Tests with Structural Breaks

\begin{tabular}{|c|c|c|c|c|c|}
\hline & \multicolumn{3}{|c|}{ Lee-Strazicich } & \multicolumn{2}{c|}{ Gregory-Hansen } \\
\hline & Lags & Breaks & Statistic & C & C/T \\
\hline Austria & 7 & 2 & -5.28 & -3.27 & -3.13 \\
\hline Belgium & 5 & 2 & -4.99 & -3.36 & -3.95 \\
\hline Finland & 8 & 2 & -4.46 & -3.50 & -4.16 \\
\hline France & 8 & 2 & $-6.26^{* *}$ & -4.12 & -4.64 \\
\hline Greece & 6 & 1 & -3.86 & -4.27 & -4.31 \\
\hline Ireland & 6 & 2 & -3.89 & -4.21 & -4.21 \\
\hline Italy & 1 & 2 & -4.71 & -3.61 & -3.72 \\
\hline Luxembourg & 8 & 2 & -4.50 & -3.78 & -3.52 \\
\hline Netherlands & 1 & 2 & -4.22 & -3.53 & -3.53 \\
\hline Portugal & 8 & 2 & -4.42 & -3.53 & -3.58 \\
\hline Spain & 8 & 1 & -3.11 & -3.54 & -4.62 \\
\hline
\end{tabular}

(Note) $* *$ is the rejection of the null hypothesis at the $5 \%$ significance level. $\mathrm{C}$ is the model including level shift; $\mathrm{C} / \mathrm{T}$ is the model including level shift with trend.

\footnotetext{
${ }^{11}$ See http://www.cba.ua.edu/ jlee/gauss.
} 
Given the absence of clear-cut results regarding the existence of a convergence process and due to the limitations of time series unit root and cointegration tests, we rely on a panel framework. Adding the individual dimension to the analysis, the use of panel data increases the power of unit root tests by raising the number of observations. Furthermore, this approach allows us to consider both heterogeneity and cross-dependence among Eurozone countries.

\section{B. Panel Analysis}

Historically, European countries have tied links for a long time, especially since the beginning of economic integration initiated after World War II. In this context of integration, European countries have shared common specificities-one of the tremendous example being the euro, and all the domains of monetary policy. Despite this apparent homogeneity, however, some heterogeneity may persist due to distinct economic characteristics across members: European construction has been done by steps and it widens gradually, incorporating new countries often considered to be less integrated to Eurozone than the founding members. Therefore, some countries known as peripheral members (like Portugal, Spain, or Greece) exhibit lower levels of GDP per capita, prices, or productivity. Assuming that Germany is at the center of our Eurozone conceptualization, we can, as Braudel (1985), divide EMU into three subsamples of countries $^{12}$ :

- the Core EMU, composed by Austria, Belgium, France, Italy, Luxembourg, and the Netherlands

- the Northern periphery, including Ireland and Finland

- the Southern periphery made by Greece, Portugal, and Spain

We assess potential price convergence dynamics across each subgroup using panel data unit root tests. To overcome the well-known problem of cross-sectional independence hypothesis among panel members (i.e., among the Eurozone countries), we apply second-generation panel unit root tests that relax this restrictive assumption required by first-generation tests. ${ }^{13,14}$ The Pesaran (2007) CIPS and the Choi (2002) tests are performed and the corresponding results are reported in Table 4, both tests considering the unit root as the null hypothesis. ${ }^{15}$ The former

\footnotetext{
${ }^{12}$ An alternative classification would have been to retain the distinction between core and peripheral countries, the latter group being composed by Greece, Ireland, Portugal, and Spain. Our choosing classification presents the advantage of distinguishing between Northern and Southern noncore countries.

${ }^{13}$ See Hurlin and Mignon (2006) and Hurlin (2010) for a detailed presentation of panel unit root tests.

${ }^{14}$ Economically, cross-section dependence can arise for several reasons, such as socioeconomic interactions and common factors. Crosscorrelation can also cause size distortions to first-generation panel tests. The cross-section dependence has been investigated using the CD test developed by Pesaran (2004) showing that such correlations exist in our samples of countries (results are available upon request to the authors).

${ }^{15}$ Matlab codes (Version 7.00) provided by Christophe Hurlin are used to implement these second-generation panel unit root tests (http://www.
} 
test is based on Dickey-Fuller-type regressions augmented with the cross-section averages of lagged levels and first differences of the individual series. The latter relies on an error-components panel model and removes the cross-section dependence by eliminating (i) individual effects using the Elliott et al. (1996) methodology (ERS) and (ii) the time trend effect by centering on the individual mean. For the sake of completeness, and as in the time-series context, we finally account for potential structural breaks in our panel setting. To this end, we rely on the Im, Lee, and Tieslau (2010) LM-test which accounts for the possible existence of structural breaks in both the level and the trend of the series under study. While other panel tests accounting for breaks are available in the literature, ${ }^{16}$ we retain the Im et al. (2010) test because (i) it specifically accounts for the usual nuisance parameter problem, (ii) it allows for the presence of breaks in both the level and the trend, and (iii) it does not depend on the size and location of the breaks but only on their number, increasing its power compared to the other existing tests.

Table 4. Second-Generation Panel Unit Root Tests (p-values)

\begin{tabular}{|c|c|c|c|c|}
\hline & Whole sample & Core & Northern Periphery & Southern Periphery \\
\hline \multicolumn{5}{|c|}{ 1970.01 1987.06 } \\
\hline Specification & $\mathrm{C}$ & $\mathrm{C}$ & $\mathrm{T}+\mathrm{C}$ & $\mathrm{C}$ \\
\hline CIPS & 0.41 & 0.95 & 0.7 & 0.42 \\
\hline \multicolumn{5}{|l|}{ Choi } \\
\hline$P_{m}$ & $0 * * *$ & $0 * * *$ & 0.79 & $0 * * *$ \\
\hline$Z$ & $0 * * *$ & $0 * * *$ & 0.71 & 0.21 \\
\hline$L^{9}$ & $0 * * *$ & $0 * * *$ & 0.69 & $0 * * *$ \\
\hline \multicolumn{5}{|c|}{ 1987.07 1998.12 } \\
\hline Specification & $\mathrm{C}$ & $\mathrm{C}$ & $\mathrm{T}+\mathrm{C}$ & $\mathrm{C}$ \\
\hline CIPS & 0.25 & $0.01 * * *$ & 0.99 & 0.99 \\
\hline \multicolumn{5}{|l|}{ Choi } \\
\hline$P_{m}$ & $0 * * *$ & $0 * * *$ & 0.73 & $0.01 * * *$ \\
\hline$Z$ & $0 * * *$ & $0 * * *$ & $0 * * *$ & $0.02 * *$ \\
\hline$L^{\$}$ & $0 * * *$ & $0 * * *$ & 0.59 & $0.02 * *$ \\
\hline \multicolumn{5}{|c|}{$1999.01 \sim 2011.07$} \\
\hline Specification & $\mathrm{C}$ & $\mathrm{T}+\mathrm{C}$ & $\mathrm{T}+\mathrm{C}$ & $\mathrm{T}+\mathrm{C}$ \\
\hline $\begin{array}{l}\text { CIPS } \\
\text { Choi }\end{array}$ & 0.84 & 0.5 & 0.99 & 0.24 \\
\hline$P_{m}$ & $0.01 * * *$ & $0 * * *$ & 0.7 & 0.85 \\
\hline$Z$ & $0.01 * * *$ & $0 * * *$ & 0.56 & 0.91 \\
\hline$L^{\beta}$ & $0.01 * * *$ & $0 * * *$ & 0.55 & 0.9 \\
\hline
\end{tabular}

$($ Note $) *(\operatorname{resp} * *, * * *)$ is the rejection of the unit root null hypothesis at the $10 \%$ (resp. 5\%, $1 \%$ ) significance level. C (resp. T+C) denotes model with individual effects (resp. individual effects and time trends). (a) For the CIPS test, all statistics are based on univariate AR(p) specifications with $p \leq 8$. (b) For the Choi's test, the optimal lag orders in the individual ERS statistics (Elliott, Rothenberg and Stock, 1996) for each series are deter-

univ-orleans.fr/deg/masters/ESA/CH/churlinR.htm).

${ }^{16}$ See Carrion-i Silvestre et al. (2005), Harris et al. (2005), and Chan and Pauwels (2009), among others. 
mined with $p \leq 8$. Under the null hypothesis the Choi's statistics are standard Normal when $\mathrm{T}$ and $\mathrm{N}$ converge jointly to infinity.

Table 5. Im, Lee and Tieslau (2010) Test Results

\begin{tabular}{|c|c|c|c|c|}
\hline & Whole sample & Core & Northern Periphery & Southern Periphery \\
\hline Test stat. & 7.56 & 7.63 & -1.24 & 5.06 \\
\hline
\end{tabular}

(Note) For Northern countries, the reported statistic corresponds to the no cross-dependence case where time effects have been included.

Results are relatively mixed and dependent on the test considered. The CIPS and Choi's tests frequently lead to different results. This difference may come from the way cross-sectional dependence is accounted for. Both tests are based on the one common factor approach. However, while Choi's test uses the orthogonalization procedure to deal with the cross-dependence problem, the CIPS test uses augmented cross-section average and therefore does not eliminate individual and time effects. In addition, while both tests consider one common factor, only the Choi's test allows for heterogeneous specification regarding the sensitivity of the factor, which is particularly relevant in the Eurozone macroeconomic context. Paying thus a particular attention to the Choi's approach, PPP relative to Germany is validated for both the whole sample and the core EMU in the three subperiods. PPP also holds for Southern periphery during the first two periods, but not after the launch of the euro. Regarding Northern periphery, there are strong evidences that PPP is violated for each subperiod. Finally, regarding the results in Table 5, the third-generation Im et al. (2010) test always fails to reject the null hypothesis, going against the validity of the PPP hypothesis. On a whole, our results put forward that price dynamics is heterogeneous among EMU members.

To complement these findings, we estimate the half-life of deviations from PPP for subgroups as well as individual countries. To this end, we use the PMG estimator developed by Pesaran, Smith, and Shin (1999). This procedure consists of estimating a panel error correction model where homogeneity across members is imposed for the long-run relationship, ${ }^{17}$ while heterogeneity is allowed in the short-run dynamics and error correction mechanisms. It combines two well-known procedures used in panel data: (i) the totally heterogeneous "mean group estimate" that consists of estimating separately $\mathrm{N}$ individual regressions and averaging the group specific coefficients and (ii) the homogeneous "pooled estimator" in which only the intercept is authorized to differ across Eurozone members.

${ }^{17}$ This hypothesis can be tested using a Hausman-type test. 
Table 6. Pooled Mean Group Estimates of the Error-Correction Term and Estimated Half-Lives

\begin{tabular}{|l|c|c|c|c|}
\hline & Whole sample & Core & Northern Periphery & Southern Periphery \\
\hline 1970.01 1987.06 & & & & \\
$\varnothing$ & -0.069 & -0.063 & No & -0.112 \\
Half-life & 9.69 & 10.65 & cointegration & 5.83 \\
\hline $1987.07 \sim 1998.12$ & & & & No \\
$\varnothing$ & -0.109 & -0.157 & cointegration & -0.067 \\
Half-life & 6 & 4.06 & & 9.99 \\
\hline 1999.01 2011.07 & -0.055 & -0.067 & No & No \\
$\varnothing$ & 12.25 & 9.99 & cointegration & cointegration \\
\hline
\end{tabular}

(Note) $\varnothing$ denotes the error-correction term estimated by the PMG method. Half-lives are expressed in months.

Table 7. Pooled Mean Group Estimates of the Error-Correction Term and Estimated Half-Lives

\begin{tabular}{|l|c|c|c|c|}
\hline Countries & & $1970.01 \sim 1987.06$ & $1987.07 \sim 1998.12$ & $1999.01 \sim 2011.07$ \\
\hline \multirow{2}{*}{ Austria } & $\varnothing$ & -0.006 & -0.37 & -0.05 \\
& Half-life & 115 & 1.5 & 13.51 \\
\hline \multirow{2}{*}{ Belgium } & $\varnothing$ & -0.08 & -0.14 & -0.01 \\
& Half-life & 8.31 & 4.59 & 68.97 \\
\hline France & $\varnothing$ & -0.13 & -0.05 & -0.15 \\
& Half-life & 4.97 & 13.51 & 4.26 \\
\hline Italy & $\varnothing$ & -0.02 & -0.03 & -0.02 \\
& Half-life & 34.31 & 22.75 & 34.31 \\
\hline Luxembourg & $\varnothing$ & -0.07 & -0.19 & -0.08 \\
& Half-life & 9.55 & 3.29 & 8.31 \\
\hline Netherlands & $\varnothing$ & -0.04 & -0.13 & -0.07 \\
& Half-life & 16.38 & 4.98 & 9.55 \\
\hline Greece & $\varnothing$ & -0.15 & -0.08 & No \\
& Half-life & 4.26 & 8.31 & cointegration \\
\hline Portugal & $\varnothing$ & -0.11 & -0.05 & No \\
& Half-life & 5.95 & 13.51 & cointegration \\
\hline Spain & $\varnothing$ & -0.07 & -0.04 & No \\
& Half-life & 9.55 & 16.98 & cointegration \\
\hline
\end{tabular}

(Note) $\varnothing$ denotes the error-correction term estimated by the PMG method. Half-lives are expressed in months. 
Tables 6 and 7 report the PMG estimates of the error-correction term and the corresponding half-lives. As shown in Table 6, the period corresponding to the implementation of the Single Act is the one for which half-lives are the smallest for the whole sample (about 6 months) and for the Core EMU (about 4 months). This is in line with the literature arguing that the Single Act has allowed to fully removing the remaining trade barriers (Engel and Rogers (2004)). This may also be linked to the requirements of nominal convergence due to entry into the monetary union. The introduction of the euro that was expected to accentuate this mechanism by improving market information, lowering trade costs and reducing uncertainty, seems to have had little effects since half lives have increased (12 months for the entire sample, 10 for the Core EMU)a finding that may be related to weaker adjustment mechanisms within the monetary union. Turning to Southern periphery, half-lives are very small in the first period (about 6 months) but increase in the second (10 months). This increase may be obviously linked to the EMS crisis and, especially, to the huge nominal devaluation encountered by the Spanish and Portuguese currencies following the enlargement of the fluctuation margins within the monetary union.

Regarding individual countries (Table 7), heterogeneity across members is even more marked. Inside the Core and during the first period, France exhibits the lowest half-life of about 5 months while it is about 34 months in Italy and 115 in Austria. During the second period, the differences tend to diminish, but the launch of the euro triggers a raise of gaps. One of the worrying result is the half-life of Belgium in the third period, being about 68 months. Such a value may indicate that this country is running out the cointegration path. Regarding the Southern group, departures from PPP have increased between the first and the second period, but they are relatively homogeneous among countries.

\section{Analysis and Scope of the Results}

Our results put forward that price dynamics is not homogeneous in (i) time and (ii) among European countries. Here, we aim at identifying the reasons of this heterogeneity across members, a fact that is highly relevant given that heterogeneity in price dynamics is at the root of the sovereign debt crisis that the EMU is experiencing.

\section{A. Heterogeneity of Price Dynamics as a Consequence of Structural Economic Heterogeneity}

One of the reasons explaining the differences in price dynamics is the Balassa-Samuelson catch-up effect that entails an elevation of the aggregate price levels in the low productivity- 
level countries. It can be considered as an asymmetric shock since the high productivity-level countries are expected to experience price stability. One of the proxies often used to model this phenomenon is the relative GDP PPP per capita.

Table 8. GDP PPP per Capita Relative to Germany in Percent between 1970 and 2010

\begin{tabular}{|l|c|c|c|c|c|}
\hline Countries & 1970 & 1987 & 1998 & 2007 & 2010 \\
\hline Austria & 94.12 & 99.95 & 102.8 & 107.2 & 105.8 \\
Belgium & 96.77 & 97.22 & 98.38 & 100.4 & 98.27 \\
Finland & 80.93 & 90.26 & 86.73 & 100.2 & 94.93 \\
France & 94.96 & 94.73 & 92.38 & 91.53 & 88.74 \\
Greece & 74.18 & 68.5 & 65.5 & 78.6 & 72.49 \\
Ireland & 62.09 & 65.74 & 98.55 & 122.9 & 107.65 \\
Italy & 86.08 & 92.9 & 91.14 & 86.11 & 80 \\
Luxembourg & 145.3 & 150.3 & 184.5 & 221.95 & 205 \\
Netherlands & 112.6 & 102.07 & 108.5 & 112.5 & 110.7 \\
Portugal & 52.98 & 57.62 & 68.01 & 65.84 & 64.86 \\
Spain & 74.92 & 74.21 & 80.03 & 85.39 & 80.6 \\
\hline
\end{tabular}

(Note) Authors' calculation on the basis of the OECD data.

Table 8 reports GDP PPP per capita relative to Germany. The 2007 value is shown to assess the effects of "subprimes" and hence "sovereign debt" crises. Regarding Southern Europe, the situations are somewhat mixed. Portugal has markedly reduced the gap relative to Germany before 1999; however, it is not totally fulfilled and differences are still consequent. Moreover, the reduction is definitely stopped after 1999 with the launch of the euro. Instead, Greece seems to have experienced a catch-up after the implementation of the single currency. As Portugal, the departure is not eliminated. Finally, Spain appears to have converged to German GDP per capita all over the period. The Balassa-Samuelson catch-up is then a satisfactory explanation for the PPP violation for Greece and Spain, but not for Portugal. Regarding Northern periphery, the Balassa-Samuelson catch-up is at play in Ireland and Finland for the whole period. Turning to the Core, interesting insights stand out. GDPs per capita relative to Germany have been relatively stable between periods (except Luxembourg, which can be considered as an outlier), providing a general background for the results found in Section 3.2. The elevated half-lives obtained for Italy during all the periods can be explained by the size of the GDP gap (relatively higher than for the other countries belonging to the Core) relative to Germany.

Nonetheless, the Balassa-Samuelson catch-up is not the unique reason of asymmetric shock appearance. The nominal exchange rate level relative to the rest of the world can also constitute a factor that can lead to divergences in price dynamics. In other words, can EMU members compete with low wage countries with a strong currency if they specialize in low-technology products? Since the competitiveness of these products is highly sensitive to costs, members specializing in low technology have to pull down their wages and also their price to recover competitiveness relative to low-wage countries. Members that specialize in high technology do 
not experience these constraints since their products are less sensitive to costs. Two different price dynamics are then at play: one pressured downward, the other unconstrained. Since the wages are not likely to decrease, members specializing in low technology will face a dramatic loss of competitiveness if they do not go up-market.

We try to control for that effect by constructing a simple index of technological specialization on the basis of the revealed comparative advantages for the CITI manufacturing indicator (see Appendix for the construction of the index). Table 9 reports the technological specialization for each country during the periods 1987 1998 and 1999 2009. Four categories of countries can be distinguished:

- Our benchmark country, Germany, specializes in industries with high technological contents: its products are innovative or positioned on the high quality segment, which allows it to discriminate its prices.

- Austria, Finland, France, and the Netherlands own at equal shares high and mediumtechnology industries. They have a lower market power than Germany even if it remains substantial.

- Belgium, Ireland, Italy, and Spain mainly specialize in medium-technology sectors and have very few high-technology industries. Moreover, low-technology sectors represent an important part of specialization in Spain and Italy.

- Greece and Portugal mostly specialize in low-technology industries, facing a strong competition in prices.

Table 9. Technological Specialization in 1987 1998 and 1999 2009

\begin{tabular}{|c|c|c|}
\hline \multicolumn{2}{|c|}{ Specialization } \\
\hline Period & $1987 \sim 1998$ & $1999 \sim 2009$ \\
\hline Austria & high technology & high technology \\
Belgium & medium technology & medium technology \\
Finland & high technology & high technology \\
France & high technology & high technology \\
Germany & superior technology & superior technology \\
Greece & low technology & low technology \\
Ireland & medium technology & medium technology \\
Italy & medium technology & medium technology \\
Luxembourg & NA & NA \\
Netherlands & high technology & high technology \\
Portugal & low technology & low technology \\
Spain & medium technology & medium technology \\
\hline
\end{tabular}

(Source) OECD.

(Note) NA: Not available. 
The heterogeneity of specialization supplemented by rigidities in wage decrease may explain the nonconvergence of Southern countries, especially Portugal, and also the elevated half-lives of Belgium and Italy without the possibility of decreasing wages (and hence prices). A strong currency induces a loss of competitiveness that translates into imbalances in goods markets, and finally a violation of PPP.

\section{B. Scope of the Results}

To our best knowledge, with the exception of Cecchetti et al. (2002), no study exists on the PPP deviation inside a monetary area. Cecchetti et al. (2002) have tested price index convergence among US cities using first-generation panel unit root tests. Comparing our results with theirs may be interesting because the US is a long-standing monetary area with strong political links and where economic integration is entire. Although Cecchetti et al. (2002) find, as we do, price convergence among US cities (i.e., validation of the PPP hypothesis), their half-lives are far higher than ours. They register between eight and nine years for their whole sample (19 cities on the 1918 to 1995 period) and about eight years for the more recent period (1976 1995). Such results would mean that the EMU is more integrated than the US, which is unlikely. The more plausible explanation lies in the data used as well as the econometric techniques that have been implemented. Cecchetti et al. (2002) consider price indexes instead of price levels, which is not appropriate for testing absolute PPP. Moreover, first-generation panel unit root tests may have been too restrictive to assess price convergence since they assume homogeneity among members, a hypothesis that is not verified as seen in the previous section.

The recent literature on OCA has mainly devoted attention to cyclical rather than structural homogeneity of the countries considered. On one hand, an empirical strand tried to assess the correlation of business cycles and the symmetry of shocks through VARs (see Bayoumi and Eichengreen [1992, 1996], among others). On the other hand, a theoretical strand focused on the means of rendering business cycles and shocks more symmetric (the endogenous criteria literature, pioneered by Frankel and Rose [1998]). Our approach revives the pioneering phase of OCA literature (Mundell, 1961; McKinnon, 1963; Kenen, 1969) that emphasizes on the structural similarities of currency union members, and stresses that these criteria may be the most important to achieved the optimality, or at least the viability, of a monetary union. Following Juselius (1995), linking PPP (goods market) and uncovered interest parity (capital market) conditions, it is possible to understand through price dynamics why structural heterogeneity among members of a currency union is a problem. In the absence of trade barriers as well as exchange rate adjustments, a violation of PPP (such a Balassa-Samuelson catch-up, but not only) leads immediately to goods market imbalances (trade deficits) that have to be compensated by capital inflows. This creates asymmetric debt emissions among members that result in fine (through long interest rates and default probability differentials) in sovereign debt crisis from part of the 
members. This mechanism seems to fit the troubles the EMU is experiencing.

\section{Conclusion}

This paper aims at investigating whether price dynamics are homogeneous across the Eurozone countries. This question is of particular interest in the current debt crisis context since heterogeneity in price dynamics may be one of the causes of the turmoil. Relying on monthly data over the January 1970 July 2011 period, we test for the absolute purchasing power parity (PPP) hypothesis through the implementation of second-generation panel unit root and cointegration tests. Our results show that price dynamics are heterogeneous depending on both the time period and the considered group of countries. More specifically, while PPP is validated for the core EMU countries, this hypothesis does not hold for Northern peripheral countries such as Ireland and Finland which experienced a Balassa-Samuelson effect. Turning to the Southern countries, namely Greece, Portugal, and Spain, PPP is observed only before the launch of the euro. This violation of the PPP on the recent period may be explained by a catch-up phenomenon as well as countries' technological specialization pattern. Our findings of heterogeneous price dynamics may be viewed as one of the possible causes of the current debt crisis that contribute to the debate relative to the viability of the monetary union.

Received 09 March 2012, Revised 21 April 2012, Accepted 02 May 2012

\section{References}

Allington, N.F.B., Kattuman, P.A. and F.A. Waldmann (2005), “One Market, One Money, One Price?”, International Journal of Central Banking 1(3), 73-115.

Arnold, I.J.M and B.A. Verhoef (2004), "External causes of euro zone inflation differentials. A re-examination of the evidence", Intereconomics 39, 254-263.

Balassa, B. (1961), “Towards a theory of economic integration”, Kyklos 14, 1-17.

Bayoumi, T. and B. Eichengreen (1992), "Shocking aspects of European monetary unification", in F. Giavazzi and F. Torres (eds.) The transition to economic and monetary union in Europe, New-York: Cambridge University Press.

Bayoumi, T. and B. Eichengreen (1996), "Ever close to heaven? An optimum currency area index for European countries", European Economic Review 41, 761-770.

Braudel, F. (1985), La dynamique du capitalisme, Flammarion.

Camarero, M., Esteve, V. and C. Tamarit (2000), "Price convergence of peripheral countries on the way to 
EMU: A time series approach", Empirical Economics 25, 149-168.

Carrion-i Silvestre, J. L., del Barrio-Castro, T. and E. Lopez-Bazo (2005), "Breaking the Panels: an Application to the GDP Per Capita", Econometrics Journal 8, 159-175.

Cecchetti, S.G., Mark, N.C. and R. Schuman (2002), "Price index convergence among United States cities", International Economic Review 43, 1081-1099.

Chan, F. and L. Pauwels (2009), "Unit Roots and Structural Breaks in Panels: Does the Model Specification Matter?", Working Paper, University of Sydney, Australia.

Choi, I. (2002), "Combination unit root tests for cross-sectionally correlated panels", Mimeo, Hong Kong University of Science and Technology.

Crucini, M.J., Telmer, C.I. and M. Zachariadis (2005), “Understanding European real exchange rates”, American Economic Review 95, 724-738.

Elliott, G., Rothenberg, T.J. and Stock, J.H. (1996), "Efficient tests for an autoregressive unit root", Econometrica $64,813-836$.

Engel, C. and J.H. Rogers (2001), "Deviation from Purchasing Power Parity: causes and welfare consequences”, Journal of International Economy 55, 29-57.

Engel, C. and J.H. Rogers (2004), "European product market integration after the euro", Economic Policy 19, 347-384.

Faber, R.P. and C.J. Stockman (2009), "A short history of price level convergence in theory in Europe", Journal of Money, Credit and Banking 41, 461-477.

Frankel, J. et A. Rose (1998), "The endogeneity of the optimum currency area criteria", The Economic Journal 108, 1009-1025.

Gregory, A. and B. Hansen (1996), "Residual-based tests for cointegration in models with regime shifts", Journal of Econometrics 70, 99-126.

Guerreiro, D. and Mignon, V. (2011), “On price convergence in Eurozone”, Working Paper EconomiX, 2011-34.

Harris, D., Leybourne, S. and B. McCabe (2005), "Panel stationarity tests for purchasing power parity with cross-sectional dependence", Journal of Business and Economic Statistics 23, 395-409.

Honohan, P. and P. Lane (2003), “Divergent inflation rates in EMU”, Economic Policy 18, 357-394.

Hurlin, C. (2010), "What would Nelson and Plosser find had they used panel unit root tests?", Applied Economics $42,1515-1531$.

Hurlin, C. and Mignon, V. (2006), "Second generation panel unit root tests”, Working Papers, HAL.

Im, K.S., Lee, J. and M. Tieslau (2010), "Stationarity of Inflation: Evidence from Panel Unit Root Tests with Trend Shifts", 20th annual Meeting of Midwest Econometrics Group, Oct. 1-2 2010, Washington University at St Louis.

Juselius, K. (1995), "Do purchasing power parity and uncovered interest rate parity hold in the long run? An example of likelihood inference in a multivariate time-series model”, Journal of Econometrics 69, 211-240.

Juselius, K. (2003), "Wage, price, and unemployment dynamics in the convergence to PPP in the Euro Area", Discussion Paper n03-01, Institute of Economics, University of Copenhagen.

Kenen, P. (1969), "The theory of optimum currency areas: an eclectic view”, in (R.Mundell and A. Swoboda 
eds.) Monetary Problems in the International Economy Chicago, University of Chicago Press.

Lee, J. and M. Strazicich (2003), "Minimum LM Unit Root Tests with Two Structural Breaks", The Review of Economics and Statistics 85, 1082-1089.

McKinnon, R. (1963), “Optimum currency areas”, American Economic Review 53, 657-665.

Mundell, R.A. (1961), “A theory of optimum currency areas”, American Economic Review 51, 715-725.

Ng, S. and P. Perron (2001), "Lag Length Selection and the Construction of Unit Root Tests with Good Size and Power", Econometrica 69, 1519-1554.

Pesaran, M.H. (2004), "General diagnostic tests for cross-section dependence in panels", CESifo Working Paper, $1233,255-260$.

Pesaran, M.H. (2007), "A simple panel unit root test in the presence of cross-section dependence", Journal of Econometrics 22, 265-312.

Pesaran, M.H., Shin, Y. and Smith, R. (1999), "Pooled mean group estimation of dynamic heterogeneous panels", Journal of the American Statistical Association 94, 621-634.

Rogers, J.H. (2007), "Monetary union, price level convergence and inflation: how close is Europe to the USA?", Journal of Monetary Economics 71, 259-270.

Sargan, J. D. and A. Bhargava (1983), "Testing for Residuals from least Square Being Generated by Gaussian Random Walk", Econometrica 51, 153-174. 


\section{Appendices}

The definition of the technological specialization is based on the revealed comparative advantages for trade microindicators in the manufacturing category (CITI database, available on OECD). Table 10 reports the sector associated to each number.

Table 10. Definition of CITI Database

\begin{tabular}{|c|c|}
\hline Index & Definition \\
\hline 15 & food products and beverages \\
\hline 16 & tobacco products \\
\hline 17 & textiles \\
\hline 18 & wearing apparel; dressing and dyeing of fur \\
\hline 19 & dressing of leather; luggage \\
\hline 20 & wood and products of wood and cork (except furniture) \\
\hline 21 & paper and paper products \\
\hline 22 & publishing, printing, and reproduction of recorded media \\
\hline 23 & coke, refined petroleum products and nuclear fuel \\
\hline 24 & chemical products \\
\hline 25 & rubber and plastic products \\
\hline 26 & nonmetallic mineral products \\
\hline 27 & basic metals \\
\hline 28 & fabricated metal products (except machinery and equipment) \\
\hline 29 & machinery and equipment n.e.c. \\
\hline 30 & office, accounting, and computing machinery \\
\hline 31 & electrical machinery and apparatus n.e.c. \\
\hline 32 & radio and television communication equipment \\
\hline 33 & medical, precision, and optical instruments \\
\hline 34 & motor vehicles, trailers, and semi-trailers \\
\hline 35 & other transport equipment \\
\hline 36 & furniture, manufacturing n.e.c. \\
\hline
\end{tabular}

(Source) CITI, OECD.

On the basis of the analysis of these indexes at a disaggregated level, we consider the following typology:

- Specialization in low-technology sectors: Indexes 15 to 21. 
- Specialization in medium-technology sectors: Indexes 22 to 28 and 36.

- Specialization in high-technology sectors: Indexes 29 to 35.

Note that index 23 has a high-technology industry, which is that of nuclear where only France specializes. Accordingly, we consider that for France, Index 23 testifies a high-technology specialization. In Table 11, we report for the two subperiods the sectors in which countries specialize.

Table 11. Specialization of Eurozone Members based on Comparative Revealed Advantages

\begin{tabular}{|c|c|c|}
\hline & \multicolumn{2}{|c|}{ Specialization } \\
\hline Period & $1987 \sim 1998$ & 1999 2009 \\
\hline Austria & $\begin{array}{c}17,19,20,21,22,25,27 \\
28,29,31,34,36\end{array}$ & $\begin{array}{l}15,16,19,20,21,22,25 \\
26,27,28,29,31,34,36\end{array}$ \\
\hline Belgium & $\begin{array}{c}15,17,23,24,25,26,27, \\
34\end{array}$ & $\begin{array}{c}15,17,21,23,24,25,26, \\
27,34\end{array}$ \\
\hline Finland & $\begin{array}{c}20,21,22,27,28,29,31,32, \\
35,36\end{array}$ & $\begin{array}{c}20,21,22,27,28,29,31, \\
32,35,36\end{array}$ \\
\hline France & $\begin{array}{c}15,22,23,24,25,26,28 \\
31,34,35\end{array}$ & $\begin{array}{c}15,21,22,23,24,25,26 \\
28,29,31,33,34,35\end{array}$ \\
\hline Germany & $\begin{array}{c}21,24,25,26,29,31,33, \\
34,35\end{array}$ & $\begin{array}{c}16,21,24,25,29,31,33, \\
34,35\end{array}$ \\
\hline Greece & $15,16,17,18,26,27$ & $\begin{array}{c}15,16,17,18,22,25,26 \\
27,28\end{array}$ \\
\hline Ireland & $15,22,24,30$ & $15,22,24,30$ \\
\hline Italy & $17,18,19,26,28,29$ & $\begin{array}{c}15,17,18,19,21,26,28, \\
29\end{array}$ \\
\hline Netherlands & $16,22,23,24,25,30,33$ & $16,22,23,24,30,33$ \\
\hline Portugal & $\begin{array}{c}15,17,18,19,20,21,26, \\
28,31,34,36\end{array}$ & $\begin{array}{c}15,16,17,18,19,20,21 \\
23,26,28,31,34,36\end{array}$ \\
\hline Spain & $\begin{array}{c}15,19,23,25,26,27,28, \\
34\end{array}$ & $\begin{array}{c}15,19,21,23,24,25,26,27, \\
28,34\end{array}$ \\
\hline
\end{tabular}

(Source) Classification established by the authors on the basis of CITI and OECD data. 


\section{Figure 1. Price Level Series (in logarithm)}
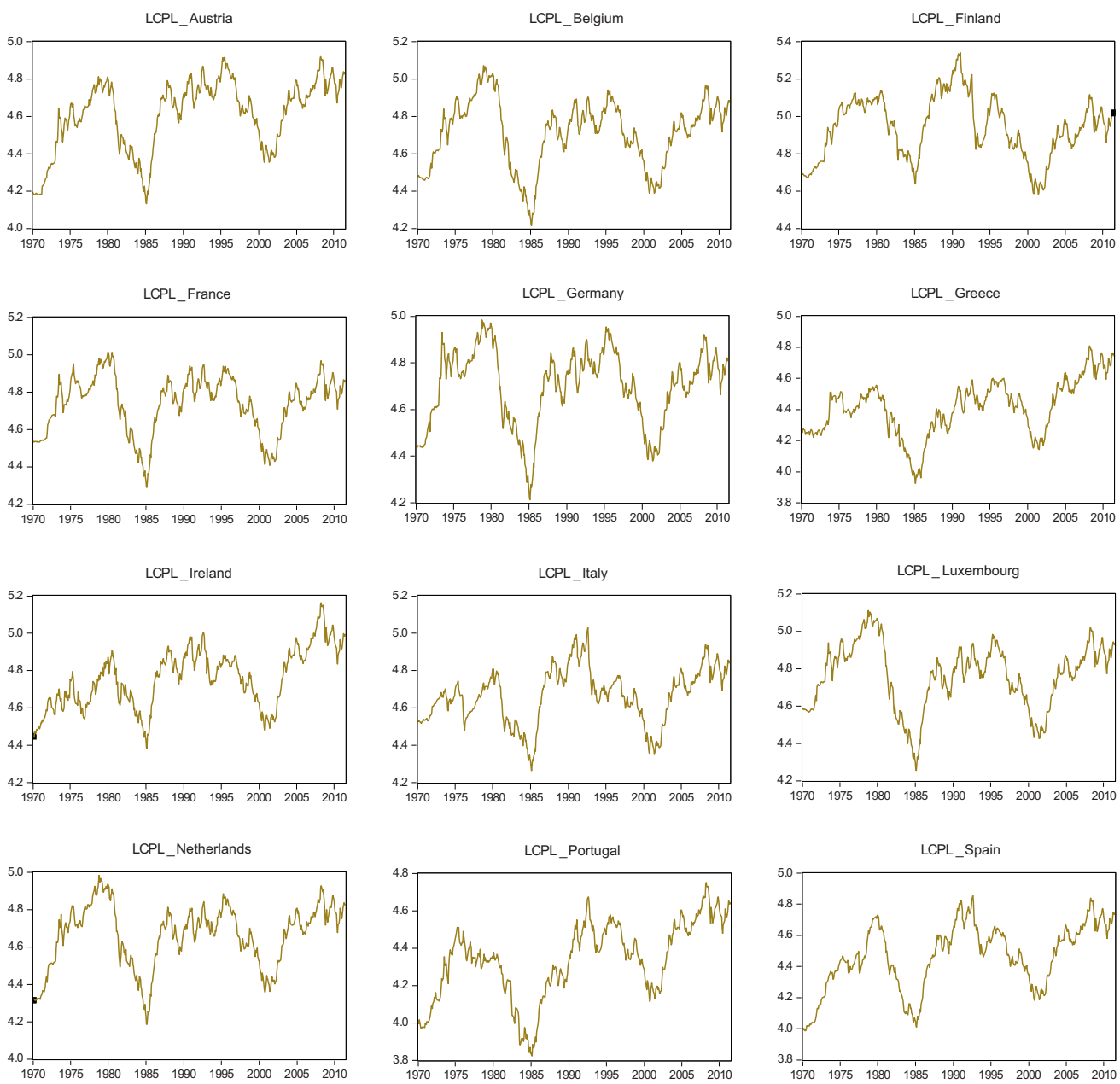